\title{
Frontonasal Prominence
}

National Cancer Institute

\section{Source}

National Cancer Institute. Frontonasal Prominence. NCI Thesaurus. Code C34182.

Two areas of thickened ectoderm that surround the ventrolateral part of the forebrain in the embryo, forming the upper half of the face and the nose during the third week of gestation. 